\title{
Crafting for Major Life Events: Implications for Technology Design and Use
}

\author{
Michael Massimi \\ Microsoft Research Cambridge \\ mmassimi@microsoft.com
}

\author{
Daniela Rosner \\ Stanford University \\ Daniela.Rosner@gmail.com
}

\begin{abstract}
Technology increasingly plays a role in the way that we prepare for, celebrate, and reflect upon major life events. Modern digital artefacts, such as Facebook messages and digital photos, now stand alongside traditional artefacts, such as guest books and heirloom jewellery, as cherished mementos of these occasions. Considering how these physical artefacts are crafted provides a useful lens for understanding the evolving relationship among digital tools, the artefacts they produce, and the major life events where these artefacts are used and imbued with meaning. In this paper, we present themes from an interview study conducted with crafters who created items for major life events including weddings, household moves, and births. Our findings outline properties of the crafting process and of the crafted items. Across all occasions, crafters saw major life events as opportunities to learn new skills and use special materials to create personalized artefacts that codified and extended interpersonal relationships. This occurred in parallel with a creative, thoughtful process to make crafts that were appropriate for each occasion and meaningful enough to be kept and treasured for years to come. We reflect on the properties of these crafters' processes and artefacts, and suggest implications for the role of digital tools and assets in relation to major life events. In particular, digital ways to reveal an artefact's provenance and relationship to an event may be useful for augmenting its symbolic meaning and its ability to represent interpersonal relationships.
\end{abstract}

Crafting, major life events, ritual, materials, design, provenance, maintenance, repair.

\section{INTRODUCTION}

Repeatedly throughout our lives, we experience major life events that give shape to our personal stories and sense of identity. These major life events include births, coming of age, weddings, deaths, divorces, and so on; they occur relatively rarely in an individual's life, and often resonate deeply in the personal sphere, bringing about significant change. Rituals often mark these events, and bring together communities of individuals to engage in a culturally-embedded ceremony (Bell, 1992).

The execution of these ceremonies involves materials in numerous ways. Participants select, arrange, and produce objects for the ritual that serve numerous purposes. In ancient rituals, craft objects (e.g., knitted shawls or ceramic pottery) indicated the solemnity or joy of an occasion. Similarly, crafted gifts (e.g., quilted blankets) were given to key participants in order to acknowledge their new status in society. Physical artefacts and symbols worked in this way to establish a sense of community and continuity through time (Bell, 1992). To this day, crafted artefacts (along with massproduced ones) may symbolize human values and aspirations as part of an event (e.g., a wedding ring can symbolize union, continuity, and fidelity). Participants may keep artefacts from the ritual as mementos of the occasion, imbuing them withmeaning and value; they may even become family heirlooms.

For technologists, there is value in understanding how physical artefacts are made and used during major life events, and how people imbue them with social value. Odom et al. (2010), for example, have explored how people ascribed new meanings to physical artefacts that they inherited following the death of a family member. In this case, the artefact's value transforms because a major life event has occurred. . People also ascribe meaning and value to artefacts - both physical and digital produced during an event. For example, digital photos and printouts of them taken during a holiday to a theme park are not only meaningful mementos, but help to constitute the event itself. (Durrant et al., 2011). Part of the holiday is the creating of photos, and creating these artefacts is what helps to make a holiday a holiday.

In studies of physical artefacts conducted with an eye towards technology design, there has been a 
thorough exploration of the properties people ascribe to artefacts after an event has occurred positioning them as found artefacts that are already imbued with values and meaning. Research has focused on these artefacts in supporting subsequent practices such as reminiscence, storytelling, and communication (Harper et al., 2008). Extending this vein of research, we inquire into the provenance of these objects. We ask who they were created for, and how they were created and used during an event. We then ask how people think about these objects in the lead up to the event, and how the meaning changes as the event unfolds and time passes.

There are many potential ways to understand this complex process; in this paper, we view this process from the perspective of craft. Craft is a process that is difficult to define, but has received considerable attention in the design and $\mathrm{HCl}$ literature in recent years (Bardzell, Rosner, and Bardzell, 2012; Gauntlett, 2011; Pye, 1968). From mosaics to knitting, prior studies of craft have shed light on how and why digital artefacts come to matter, e.g. by revealing intimate moments (Rosner and Ryokai, 2010) or encouraging making with ingenuity (Bardzell, Rosner, and Bardzell, 2012). While for some the term "craft" primarily connotes cultural tradition, for others it suggests skillful technique or care. Further complicated by its relationship to "design" and "art," craft artefacts often symbolize connections between humans, objects and society, producing unique communicative patterns over time (Gauntlett, 2011). As such, craft is not a trivial pursuit, but a means through which people create themselves and the worlds around them, assembling and maintaining specific modes of inquiry, cultural knowledge and social practice (Dormer, 1997; Sennett, 2008). Craft is both a process and an end in itself (Dormer, 1997; Sennett, 2008; Pye, 1968).

Given the range of ways that one could explore major life events, we find craft complementary to psychological or sociological approaches. Many accounts of major life events see them as part of narrative and the performance of identity (Gergen, 1992), or as markers of change in social status or structure (Bell, 1992). A craft perspective helps to ground our inquiry by emphasizing materials and handiwork in addition to these invisible phenomena. When social science does attend to the physical (e.g., in studies of material culture), it reports on what found artefacts can tell us about someone's personality or society (Miller, 2010). Craft reminds us that these artefacts are manmade assemblages of materials that have been purposefully brought together and used to actively construct meaning (sometimes during major life events) rather than passive symbols.
Drawing on the craft perspective, we report on findings from an interview study with crafters who have made items specifically for a major life event - their own, or someone else's. We report on the properties of their crafting process, and on the properties of the objects they created. In particular, we delineate what makes the process and outcome of crafting for a life event different from crafting more generally, and point to implications these differences might have for the design and use of technology during major life events.

\section{METHOD}

We performed 9 semi-structured interviews with people who self-identified as "crafters". Participants were recruited through postings to Craigslist and local community websites, and through snowball sampling (Table 1). Interviews were performed via telephone or instant message, and all were recorded and transcribed prior to analysis. Each interview lasted 30-90 minutes. Participants were asked to respond to questions primarily with respect to their most recent experience crafting for a life event, but we also probed about other less recent experiences crafting items for life events.

Two researchers independently developed themes based on the transcripts and a memoing process. The researchers then jointly reorganized and elaborated these themes through discussion.

Table 1: Participant demographics and crafting projects.

\begin{tabular}{|c|c|c|c|c|}
\hline Part. & Age & Sex & Crafts & Events \\
\hline$P 1$ & 29 & $F$ & $\begin{array}{l}\text { Holiday and } \\
\text { wedding } \\
\text { decorations }\end{array}$ & $\begin{array}{l}\text { Weddings, } \\
\text { holidays }\end{array}$ \\
\hline$P 2$ & 37 & $F$ & $\begin{array}{l}\text { Knitting, crochet, } \\
\text { beading }\end{array}$ & $\begin{array}{l}\text { Births, new } \\
\text { homes, } \\
\text { weddings }\end{array}$ \\
\hline P3 & 24 & $F$ & Sewing, textiles & $\begin{array}{l}\text { Birthdays, } \\
\text { holidays, new } \\
\text { homes }\end{array}$ \\
\hline$P 4$ & 38 & $M$ & $\begin{array}{l}\text { Photo albums, } \\
\text { knitting, } \\
\text { woodcarving }\end{array}$ & $\begin{array}{l}\text { Birthdays, } \\
\text { weddings }\end{array}$ \\
\hline P5 & 27 & $F$ & $\begin{array}{l}\text { Paper invitations, } \\
\text { wedding } \\
\text { centrepieces }\end{array}$ & Weddings \\
\hline$P 6$ & 32 & $M$ & Paper art & $\begin{array}{l}\text { Holidays, } \\
\text { funerals, } \\
\text { weddings }\end{array}$ \\
\hline$P 7$ & 25 & $M$ & $\begin{array}{l}\text { Painting, } \\
\text { woodworking, } \\
\text { Christmas } \\
\text { ornaments }\end{array}$ & $\begin{array}{l}\text { Holidays, } \\
\text { weddings }\end{array}$ \\
\hline P8 & 20 & $F$ & $\begin{array}{l}\text { Haberdashery, } \\
\text { cross-stitching, } \\
\text { needlework }\end{array}$ & $\begin{array}{l}\text { Anniversaries } \\
\text { birthdays, } \\
\text { weddings }\end{array}$ \\
\hline$P 9$ & 53 & $F$ & $\begin{array}{l}\text { Crochet, gift } \\
\text { boxes, jewellery, } \\
\text { leather pouches }\end{array}$ & $\begin{array}{l}\text { Birthdays, } \\
\text { weddings }\end{array}$ \\
\hline
\end{tabular}




\section{THEMES}

We first present four themes emerging from the interviews before moving into how these themes might be reinterpreted in the context of technology design. It should be noted that these themes represent a limited sampling of crafters and their practices, but provide a descriptive account of how these crafters see their process and production in relationship to major life events.

\section{I: Life Events are Opportunities to Craft}

Whether the winter holidays were approaching or a good friend was planning a wedding, upcoming events offered our participants opportunities to make something new. Crafters described having multiple projects going on at a time - some for fun, some as a challenge, and some as gifts. For major life events, craft projects were times to learn new techniques and select special materials. As P2 said, "I was just trying to look at what else you can do with knitting besides baby sweaters...l'm trying something new that I haven't tried before." P7 sought out how-to instructions and videos to push the limits of his existing skillset, making pickles and Christmas cookie ornaments: "almost anything you can learn to make." While P6 stuck with the particular medium and technique of paper cutting, he still came up with other ways to challenge himself - e.g., creating work on-the-fly in front of clients at craft shows. Major life events seemed to make way for unusual circumstances, materials, or tools for craft production. The craft projects that focused on major life events were, thus, seen differently from other types.

When an event is important and singular, crafters often felt that the artefacts they created for the event should be similarly one-of-a-kind. For some participants, this goal of creating a unique artefact could bring on heightened expectations for technical prowess and material integrity. Crafters placed these expectations on themselves; P2 spoke for other interviewees when she described not wanting to give something of poor quality to someone else.

Sometimes this increased expectation for craftsmanship encouraged crafters to forge essentialist judgments of good and bad. Major life events created a situation where crafters took stock of the quality and quantity of their work to date, and instigated a process of carving out a project that challenged their competencies and ambitions. For example, P1 and P8 both felt that creating an item for a wedding demanded "perfection." For P5, decisions were made against clear goals for the quality of his work; a font could be, in his words, "correct." The event seemed to prompt an elevated concern for symbolic value in the crafted artefact.
In addition, the timing of an event placed practical constraints on the crafting process. P3 noted how crafting for an upcoming event creates a deadline so that the item can be used or presented during a gathering. She contrasted this with her other crafting projects, where her interest and focus might drift, leaving a project halfway done.

These heightened expectations apply to the craft process as well as the output. Originality was a common theme: "I want to think of something different this time since it's a more special occasion," P4 explained. The way that design projects were approached required additional care and thought. At the same time, and despite using new techniques or materials, there is an expectation that more will be produced and more efficiently than in usual projects. For example, P5 was facing the daunting task of creating hundreds of favours and centrepieces for her wedding. After she described this stressful process, she compared it against another one of her more mundane craft projects - "cooking is Zen to me."

Part of the process of any craft project is selecting the right materials to match the purpose of the project. P5, for example, talked about one material that she chose to "denote a classy feeling" and represent luxury. The emotional weight associated with important life events enabled crafters to justify letting go of valuable material. P2 was happy to use her "good wool" for the right occasion, as the best fibres would often build up over years. P4 saw a connection between rare materials and rare events: "Oh that's gold foil fused with actual gold. It automatically dawns on you, gold's just a classic material that always entails luxury and precious moments."

Alongside the use of precious materials, participants found that major events afforded opportunities to save money. Tightening event budgets would often lead to inventive alternatives that were both useful and fulfilling to our interviewees. As P9 said: "I find that so satisfying that I can still make things that are affordable to buy." Yet remaining frugal was not always easy. For P1 and P4, it involved traveling distances to discover discount craft stores or "dollar stores" with less expensive materials. "I just try really hard to keep it really frugal," P9 told us. "Just because a painter takes 60 at 8 hours a day, it doesn't necessarily mean that you can charge 45 dollars for an hour." Minimizing the cost to clients was part and parcel of interviewees' moral claims to integrity and quality.

Summing up this theme, major life events caused crafters to take on more elaborate and special projects than they normally do, resulting in changes to both their process and their choice of materials. 


\section{II: Crafting to Personalize Life Events}

Along with saving money, being able to customize materials has been identified as a key motivator for engaging in craft (Shove et al., 2007). This held true in our interviews, yet the customizations were often symbolic rather than functional or economical. P8 cross-stitched hip-hop lyrics and chess pieces onto a pillow that she gave to her boyfriend on his birthday, noting that hip-hop and chess don't normally go together, but that they reflected his unique blend of interests. P4 noted "I thought about [the recipient's] personality, what I thought he might like" when choosing colours in a portrait. Major life events present opportunities to enshrine aspects of one's history or personality in an object, and by virtue of including the object in an event, an opportunity to celebrate that symbolic meaning.

In addition to crafting to reflect personality, participants personalized their crafts to bring to mind past experiences. For example, for a friend's move into a new home, P3 said "I decided...to [craft] her an owl doorstop because we went to the zoo recently and saw some owls... I put a little quote underneath the owl while we were at the zoo so it's like a memory of our day." Similarly, P5 made wedding invitations which contained a photograph of the Pantheon - the place where her fiancé proposed. Major life events created marked points in time where participants reflected on the past in light of the present; crafted objects were important parts of this process.

Here there are opportunities for technology to shape the materials used during the life event by symbolically referencing aspects of personality or past shared experiences. For example, software might turn to Facebook or shared calendars to suggest past events that people have shared, and offer opportunities to incorporate these into the crafting experience. Similarly, systems that can detect a user's interests or personality traits (e.g., through analysis of Twitter feeds or shopping behaviours) could be brought into other systems in order to inspire reflection on the individual's preferences and encourage personalization.

\section{III: Craft Artefacts Symbolize Relationships}

Craft materials and techniques were often used to stand in for the same relationships as the event. For instance, P9 used pieces of her client's great grandmother's broken vintage plate in bracelets for her client's family celebration. She identified decorative apples and pears on the ceramics shards, used her rock tumbling tools to smooth out the edges, and embedded the shards in metal with her jeweller's tools. By giving new life to broken ceramic chards she reflected the sentiments of the event: re-igniting old familial bonds.
Similarly, P5 described how important it was that the wedding invitations be paper and not electronic. She felt that the physicality of the invitation "just felt personal and intimate in that it was something people would be holding in their hands." In this case, the invitation acts as a stand-in for her own presence; the physicality and imagined shared handwork evokes an affectionate emotional bond between the bride-to-be and her family and friends.

The $\mathrm{HCl}$ and $\mathrm{CSCW}$ literature has explored how technology can mediate interpersonal communication and expression. One way to potentially improve these technologies is by allowing them to be adjusted or personalized to suit the relationship and occasion. General-purpose technologies (like SMS, email, etc.) are well-suited to everyday communication, but for these special events, more symbolic modes of communication could be opened up and explored.

Indeed major life events prompt friends and family to gather together for a period of time. To mirror this brief period of togetherness, systems might allow particular kinds of communications to occur only for the duration of the event, or systems might allow "limited-edition" digital artefacts to be produced only when gathered together as a community. For example, a provided mobile phone app might only work during a special event. The inability to reproduce the structure or character of the digital artefacts created by the app might preserve their symbolic, totemic nature; they are forged and imbued with meaning during a community's gathering at a particular point in time.

\section{IV: Receiving and Keeping Crafted Items}

Major life events offer opportunities to present gifts to people that we care about. All participants expressed affection by putting more time and effort than normal into their crafts. In response, the crafters expected the recipients of their gifts to acknowledge their efforts, and show appreciation of the item by using it during or after the event. P4, P6, P7, and P8 all talked about crafting as a process of reification: it concretizes a relationship between people in the material, and the event itself is the point in time where this relationship is brought forward, inspected, and celebrated.

In this vein, and because of the heightened circumstances associated with life events, participants designed their craft objects with an eye towards future use and keeping. P5, for example, talked about how she felt her wedding invitations should be "designed for the scrapbook." While participants talked about functionality and aesthetics as key properties of their crafted objects, their durability as indicators of a relationship was also something to bear in mind. 
While crafting was seen as a way to articulate affection and the value of the relationship between people, at least one participant was worried about giving too many crafted gifts. P3 stated, "I think that for a once in a lifetime event a crafted item can be even more special. I tend to not always craft people gifts because it gets a bit, it loses its meaning... If I made items for people for every event they would then... it would lose the magic that I put in my effort." This highlights an important point - just as relationships require room to 'breathe' in a sense, giving too many handcrafted gifts can be overly onerous on the recipient who may be expected to match the time and effort spent on the relationship.

Furthermore, this speaks to the process of crafting a gift as part of the relationship work - gifts can be too much, or too expected, or too inappropriate. Crafters work to ensure that their gift is received in a context that is appropriate to the relationship. Indeed, a prior study of gifting (Rosner and Ryokai, 2011) found the addition of social annotations around crafted artefacts could amplify expectations for appreciation. Giving a crafted object entails, in P7's words, "giving away a piece of yourself." Major life events offer sanctioned times where this excess of affection, time, and effort are permitted, but this expectation is a double-edged sword: it is an opportunity for grand acts of craftwork and expression, but it is also an opportunity to fall short of expectations.

\section{IMPLICATIONS FOR DESIGN}

Having laid out some of the findings from our set of interviews, we now revisit these ideas to consider what they might mean for technology design and use at major life events more generally. In these implications we are particularly interested in two areas: (a) how technology could support crafters who are creating digital or physical artefacts for life events, and (b) how the lessons and techniques of crafting could be made more readily available to a more general audience.

\section{Highlighting the Unusual: Imbuing Technology with Symbolic Value}

Technology can make things that are identical; yet craft is often about making one-of-a-kinds. These tensions could be explored by designing unusual or idiosyncratic interactions. Rather than open a digital e-vite or e-card by clicking a link, crafting activities might involve allowing users to define the circumstances of that unwrapping or the aesthetic of the design. Finding ways to return some of the "hand-craftedness" to mass-produced digital artefacts could imbue these items with expression and symbolic meaning. This is more than offering more options to users about how their digital artefacts are encountered; this suggests that tools for crafting experiences should be open-ended and support imaginative ways of authoring.

As part of the motivation to create something extraordinary for a major life event, crafters reported trying new techniques or learning new skills. If major life events are opportunities for crafters to learn something new, technology might be able to support this process by suggesting new techniques or materials that are normally not encountered. For more general audiences, this suggests that major life events are times to learn something new -- whether it is trying out a new website or feature, life events might be opportune times for software to assist users in reaching outside their comfort zones.

\section{Revealing an Object's Provenance}

Crafters wanted the recipients of their gifts to appreciate the effort and affection that accompanied the production of their crafts. Recipients might be able to glean a rough sense of this from the choice of material or perceived difficulty of the project. However, technology can provide a richer appreciation of the provenance of an item by letting people capture, share, and revisit the craft process in new ways by augmenting the item itself (Rosner and Ryokai, 2010). The human relationship is critical to capture in the object.

Our work demonstrates two aspects of human relationships are particularly important: the shared history of the crafter and recipient, and the recipient's personality and interests. First, supporting shared history can come from detecting physical co-presence at an event (e.g., the day at the zoo). Surfacing past shared experiences can be a useful resource for crafting, and may be readily accomplished on social networking sites that track events such as Facebook. Related resources may be at hand in the same system.

Second, to show the crafter's understanding of the recipient's personality and interests, a system could reveal some of the emotional and thoughtfulness that accompanies the craft process. For example, recall P8 stitched hip-hop lyrics into a pillow for her boyfriend. A system that shows she was listening to that album while stitching could reveal some of this otherwise invisible thoughtfulness. Technology, like craft, may be able to provide artful ways to help people feel known and understood.

We also saw that crafters created objects that they saw as worth keeping even before they took form. This intention to "design for the scrapbook" may precede the crafting itself. P5, even before she had a design for her wedding invitation, knew that it would be a treasured memento in the years following her wedding. While the best materials might be chosen, and the outcome might be 
beautiful, the real importance comes from the object's involvement in the event.

\section{Designing for Reparation and Maintenance}

We found that craft artefacts that are used in major life events continue to last as a result of ongoing care and preservation. This maintenance to an item helps it carry a certain sense of authenticity or charm. Repairing and giving new life to digital materials after an occasion might similarly extend the life of the technological artefact and the event. To use the idea of a wedding website, this website might be carefully crafted and produced for the wedding, but repurposed afterwards in order to reflect the new family. The husband and wife might have their own sections on the site; when children come along, they receive their own as well. The maintenance of this website - originally for the wedding - becomes an important process for representing the structure and value of a new, growing family. In our work, we saw crafters create a series of crafts that mirror this type of continuity of care - for example, a portrait might be created for one member of the family, but then later extended to include other members.

When crafts break, repairing the object is of course not the only possible action. These objects could be repurposed in new ways. For example, broken shards of glass could be incorporated into a card or lampshade. In terms of technology, we might productively think about how broken items can be woven into a computationally enhanced "mixed media" gift. Layering interactive experiences on top of the sensual experience of the craft object can be a productive and powerful way to restore, reinterpret, or augment an object's material value.

\section{CONCLUSION}

In this paper we have explored some of the issues wrapped up in the crafting of items as they relate to major life events. In so doing we have elaborated the properties of craft objects and processes, and how life events transform these properties by introducing heightened circumstances, alternative options for expressing emotion around relationships, and the ways that objects endure following the event. Technology can benefit from exploring these unusual properties and processes in an effort to better support users' craft efforts. Technology might be employed to make digital and physical artefacts more capable of supporting the meaning layered onto them by major life events. The process of craft demonstrates that this may be achieved through techniques for revealing the provenance of the object, and by revealing its repair and maintenance over the years.

\section{REFERENCES}

Bardzell, S., D. K. Rosner, and J. Bardzell. (2012) Crafting quality in design: integrity, creativity, and public sensibility. DIS 2012, Newcastle, UK, 2012, 11-20. ACM Press, New York.

Bell, C. (1992) Ritual theory, ritual practice. Oxford University Press, Oxford, UK.

Dormer, P. (1997) The culture of craft. Manchester University Press, Manchester, UK.

Durrant, A, Rowland, D., Kirk, D., Benford, S., Fischer, J., and McAuley, D. (2011) Automics: souvenir generating photoware for theme parks. CHI 2011, Vancouver, BC, Canada, 2011, 17671776. ACM Press, New York.

Gauntlett, D. (2011) Making is connecting. Polity, Cambridge, UK.

Gergen, K. (1992) The saturated self: Dilemmas of identity in contemporary life. Basic Books.

Harper, R., Rodden, T., Rogers, Y. and Sellen, A. (2008) Being human: Human-computer interaction in the year 2020. Microsoft Press, Cambridge, UK.

Jackson, S. J., A. Pompe, and G. Krieshok. (2012) Repair worlds: maintenance, repair, and ICT for development in rural Namibia. In Proceedings of CSCW'12. ACM.

Joyce, R. (2012) From place to place: Provenience, provenance, and archaeology. In Provenance: History of Art and Ownership, Gail Feigenbaum and Inge Reist, (eds.) Getty Research Institute, Los Angeles.

McCullough, M. (1998) Abstracting craft: The practiced digital hand. MIT Press, Cambridge, MA, USA.

Miller, D. (2010) Stuff. Polity Press, Cambridge UK.

Odom, W., Harper, R., Sellen, A., Kirk, D., \& Banks, R. (2010) Passing on \& putting to rest: Understanding bereavement in the context of interactive technologies. CHI 2010, Atlanta, GA, USA, 2010, 1831-1840. ACM Press, New York.

Pye, D. (1968) The nature and art of workmanship. Cambridge University Press, Cambridge, UK.

Rosner, D. K, and K. Ryokai. (2010) Spyn: augmenting the creative and communicative potential of craft. CHI 2010, Atlanta, GA, USA, 2010, 2407-2416. ACM Press, New York.

Sennett, R. (2008) The craftsman. Yale University Press, New Haven, RI, USA.

Shove, E. et al. (2007) The design of everyday life. Oxford University Press, Oxford, UK. 